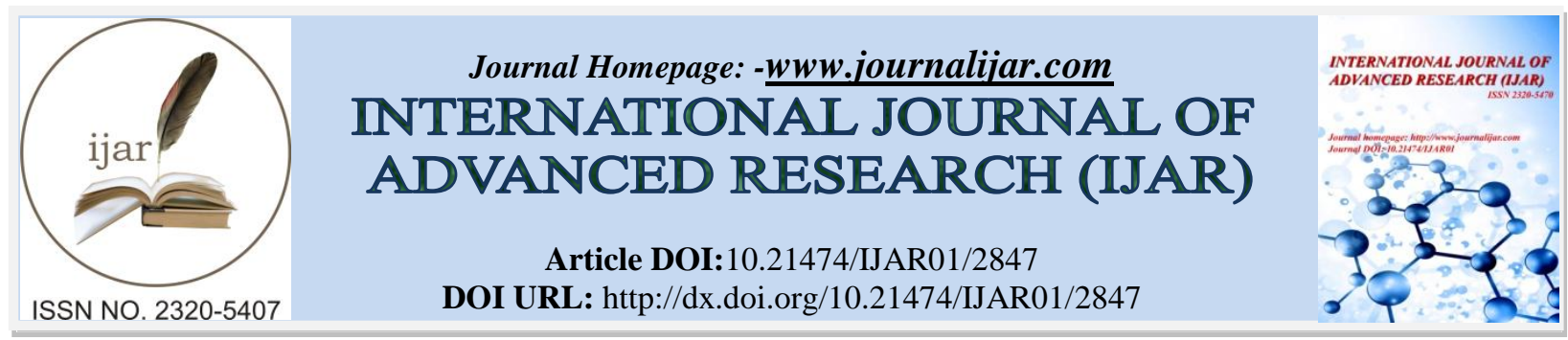

RESEARCH ARTICLE

\title{
PSYCHOLOGICAL STRESS AMONG UNDERGRADUATE MEDICAL STUDENTS OF SAUDI ARABIA: A CROSS SECTIONAL SURVEY
}

\footnotetext{
${ }^{*}$ Mudassar Ali Roomi ${ }^{1}$, Alharbi Abdulrhman Obaid ${ }^{2}$, Hamoud Mohammed Alshaya ${ }^{3}$ and Khalid Alobeiwi ${ }^{4}$.

1. MPhil Physiology, Assistant Professor in Physiology, School of Health Sciences, College of Medicine, Nursing and Health Sciences, Fiji National University, Fiji Islands.

2. MBBS, Medical Intern at King Fahad Specialist Hospital, Buraidah, Qassim.

3. MBBS, Intern Alzulfi General Hospital, Saudi Arabia.

4. MSc, RRT-NPS, ACCS, Alzulfi General Hospital, Saudi Arabia.
}

\section{Manuscript Info}

\section{Manuscript History}

Received: 19 November 2016

Final Accepted: 21 December 2016

Published: January 2017

Key words:-

Psychological Stress, Mental Health, University Students, Kingdom of Saudi Arabia.

\begin{abstract}
Background: Psychological stress can negatively affect learning and performance of medical students. Medical studies are considered intrinsically more stressful than many other disciplines. This study was conducted to investigate stress among undergraduate medical students of Saudi Arabia, and to compare stress between pre-clinical and clinical students, and to compare stress between male and female students.

Methods: This cross-sectional survey was conducted in December 2016 among medical students by using a self-administered questionnaire. The data were entered and analyzed using IBM-SPSS20. The data were summarized and analyzed by frequencies, percentages, means, standard deviation and Chi-square test.

Results: A total of 119 participants (54.6\% males, $45.4 \%$ females) with mean age of $21.8 \pm 2.1$ years participated in this study. Severe and moderate stress was present among $78 \%$ and $20 \%$ of the participants, respectively. Prevalence of stress was high in all the medical students irrespective of whether they were in pre-clinical or clinical years of study; there was no statistically significant difference between them. Majority (77\%) of the male students had severe stress as compared to $79.6 \%$ of the female students; there was no statistically significant difference between them.

Conclusions: Most of the medical students of Saudi Arabia perceive their studies and training as either moderately or severely stressful. The risk of stress was high among most of the participants irrespective of their gender, and pre-clinical or clinical years of study during MBBS. It is recommended that stress management courses should be included in the curriculum of undergraduate medical students.
\end{abstract}

Copy Right, IJAR, 2016,. All rights reserved.

\section{Introduction:-}

Stress can be defined as any challenge to homeostasis or to our body's ability to keep the internal environment constant(Bansal and Bhave, 2006). In psychology, stress can be defined as a feeling of strain and pressure. Stress is body's non-specific response to demands or to any disturbance in the environment. It is a process which enables us 
to perceive and cope with challenges or threats (Al-Dubai et al., 2011).Stress can be good or bad. 'Good stress' is called as eustress. Eustress is a form of stress in which a person perceives a stressor as positive; it motivates and inspires the person to continue working. 'Bad stress' is called as distress and it is a negative form of stress which demotivates a person. Distress occurs when a person perceives that his capabilities or resources are less than the demands; stressors create tension and there is no fun in the challenge while a person is distressed(Le Fevre et al., 2006).

Too much stress can affect physical and psychological health of individuals (Folkman, 1984). Perceived stress can create emotional instabilities leading to relationship problems, sleep disturbance, low self-esteem, anxiety, depression,drug addiction, and suicidal tendencies(Shapiro et al., 2000; Moffat et al., 2004; Stecker, 2004; Yousafzai et al., 2009).Stress may also decrease the learning abilitiesand academic performance of students. Moreover, it canadversely affect the ability of doctors to provide high quality care (Firth-Cozens, 2003).

Tertiary medical education is regarded generally as being highly stressful. It has been observed that medical students and resident doctors experience more stress than students of other disciplines(Stewartet al., 1999; Aktekin et al., 2001; Dyrbye et al., 2006). Medical students are prone to stress development due to vastness of their curriculum, length and depth of their courses, inadequate leisure time,lack of holidays, financial burden and career choices(Stecker, 2004; Yousafzai et al., 2009; Waghachavare et al., 2013; Oboko et al., 2015). Some studies suggest that medial students are most prone to stress in their $1^{\text {st }}$ year of study due to tremendous change in their lifestyle(Stewartet al., 1999; Dyrbye et al., 2006). Another study suggests that medical students are at risk of stress during transition from pre-clinical years to clinical training(Oboko et al., 2015).

There seems to be limited information in Saudi Arabia relating to this important global issue, especially on comparison of stress between male and female students, and between pre-clinical and clinical students. Therefore, this study was conducted to: a) assess the degree of stress among undergraduate medical students of Saudi Arabia, b) compare stress between medical students of pre-clinical years and clinical years, and c) compare stress between male and female medical students.

\section{Methodology:-}

This cross-sectional survey was conducted in December 2016 among medical students enrolled in various medical colleges of Saudi Arabia. The participants were male and female medical students aged $\geq 18$ years studying in various years of MBBS from year 1 through year 6. A self-administered online questionnaire was created using Google Forms. The questionnaire had two sections; section 1 contained information on demographic characteristics of the participants while section 2 contained 25 standard questions to assess psychological stress. Section 2 of the questionnaire was taken from the website of International Stress Management Association-UK (ISMA, 2013).

Information on participants' age, gender and year of study were obtained. Medical students in years 1-3 and 4-6 of MBBS were considered doing their pre-clinical and clinical studies, respectively. Each participant was supposed to answer each of the 25 questions as 'Yes' or 'No'. 'Yes' carried 1 score and 'No' carried 0 score. Scores of all the 25 questions answered by a participant were added up. A participant with total score of 0-4 was supposed to have least risk of stress. A total score of 5-13 meant that the participant was more likely (moderate risk) to suffer from stress and stress-related illness. Stress score $\geq 14$ meant that the participant is most prone (severe risk) to stress and stress-related illness.

All the participants were informed about the nature and scope of the study before their voluntary participation. To ensure anonymity, no questions about the name of the institution or the name of student were included in the questionnaire. We assured confidentiality of all the data. Moreover, we ensured to fulfill the ethical considerations in line with Helsinki Declaration.

The data were double entered and analyzed by using IBM Statistical Package for Social Sciences (SPSS) version 20. The data were cross checked to ensure accuracy. The data were summarized and analyzed by frequencies, percentages, means, standard deviation and Chi-square test. A $p$-value of $\leq 0.05$ was considered statistically significant. 


\section{Results:-}

A total of 119 participants (54.6\% males, $45.4 \%$ females) with age of $21.8 \pm 2.1$ (18-28) years participated in this study. More than half (61.3\%) of the participants were students of pre-clinical (1-3) years and the rest (38.7\%) were students of clinical (4-6) years (Table 1).

Table 1:-Demographic characteristics of the participants $(\mathrm{n}=119)$

\begin{tabular}{|l|l|}
\hline Demographic characteristics & Frequency (\%) \\
\hline Age: Mean \pm SD (Range) & $21.8 \pm 2.1(18-28)$ years \\
\hline Gender & $65(54.6)$ \\
\hline Male & $54(45.4)$ \\
\hline Female & $23(19.3)$ \\
\hline Year of study during MBBS & $24(20.2)$ \\
\hline 1 & $26(21.8)$ \\
\hline 2 & $12(10.1)$ \\
\hline 3 & $9(7.6)$ \\
\hline 4 & $25(21.0)$ \\
\hline 5 & $73(61.3)$ \\
\hline 6 & $46(38.7)$ \\
\hline Pre-clinical or clinical students &
\end{tabular}

Cumulative responses of the participants to each question of the stress questionnaire are given in Table 2. Except questions 18, 20, 21 and 24, participants have predominantly reported a 'Yes' to all the questions of the stress questionnaire.

Table 2:-Participants' cumulative responses to each of the 25 questions of the stress questionnaire

\begin{tabular}{|c|c|c|c|c|}
\hline \multirow[t]{2}{*}{ Q.No. } & \multirow[t]{2}{*}{ Questions } & \multicolumn{2}{|c|}{$\begin{array}{l}\text { Participants' } \\
\text { Response }\end{array}$} & \multirow{2}{*}{$\begin{array}{l}\text { Total } \\
\text { responses } \\
\text { from the } \\
\text { participants }\end{array}$} \\
\hline & & $\begin{array}{l}\text { Yes } \\
\text { n }(\%)\end{array}$ & $\begin{array}{l}\text { No } \\
\text { n }(\%)\end{array}$ & \\
\hline 1. & I frequently bring work home at night & $93(78.8)$ & $25(21.2)$ & 118 \\
\hline 2. & Not enough hours in the day to do all the things that I must do & $89(75.4)$ & $29(24.6)$ & 118 \\
\hline 3. & I deny or ignore problems in the hope that they will go away & $65(54.6)$ & $54(45.4)$ & 119 \\
\hline 4. & I do the jobs myself to ensure they are done properly & $110(92.4)$ & $9(7.6)$ & 119 \\
\hline 5. & I underestimate how long it takes to do things & $80(67.2)$ & $39(32.8)$ & 119 \\
\hline 6. & $\begin{array}{l}\text { I feel that there are too many deadlines in my work / life that are } \\
\text { difficult to meet }\end{array}$ & $93(80.9)$ & $22(19.1)$ & 115 \\
\hline 7. & My self-confidence / self-esteem is lower than I would like it to be & $82(69.5)$ & $36(30.5)$ & 118 \\
\hline 8. & I frequently have guilty feelings if I relax and do nothing & $100(84.7)$ & $18(15.3)$ & 118 \\
\hline 9. & $\begin{array}{l}\text { I find myself thinking about problems even when I am supposed to } \\
\text { be relaxing }\end{array}$ & $103(88)$ & $14(12)$ & 117 \\
\hline 10 . & I feel fatigued or tired even when I wake after an adequate sleep & $89(76.7)$ & $27(23.3)$ & 116 \\
\hline 11. & $\begin{array}{l}\text { I often nod or finish other people's sentences for them when they } \\
\text { speak slowly }\end{array}$ & $78(67.2)$ & $38(32.8)$ & 116 \\
\hline 12. & I have a tendency to eat, talk, walk and drive quickly & $81(69.8)$ & $35(30.2)$ & 116 \\
\hline 13. & $\begin{array}{l}\text { My appetite has changed, have either a desire to binge or have a } \\
\text { loss of appetite / may skip meals }\end{array}$ & $85(73.3)$ & $31(26.7)$ & 116 \\
\hline 14. & $\begin{array}{l}\text { I feel irritated or angry if the car or traffic in front seems to be } \\
\text { going too slowly/I become very frustrated at having to wait in a } \\
\text { queue }\end{array}$ & $75(64.7)$ & $41(35.3)$ & 116 \\
\hline 15 . & $\begin{array}{l}\text { If something or someone really annoys me I will bottle up my } \\
\text { feelings }\end{array}$ & $71(61.2)$ & $45(38.8)$ & 116 \\
\hline 16. & When I play sport or games, I really try to win whoever I play & $86(74.1)$ & $30(25.9)$ & 116 \\
\hline
\end{tabular}




\begin{tabular}{|r|l|l|l|l|}
\hline 17. & $\begin{array}{l}\text { I experience mood swings, difficulty making decisions, } \\
\text { concentration and memory is impaired }\end{array}$ & $90(77.6)$ & $26(22.4)$ & 116 \\
\hline 18. & $\begin{array}{l}\text { I find fault and criticize others rather than praising, even if it is } \\
\text { deserved }\end{array}$ & $49(43)$ & $65(57)$ & 114 \\
\hline 19. & $\begin{array}{l}\text { I seem to be listening even though I am preoccupied with my own } \\
\text { thoughts }\end{array}$ & $86(74.1)$ & $30(25.9)$ & 116 \\
\hline 20. & My sex drive is lower, can experience changes to menstrual cycle & $38(34.9)$ & $71(65.1)$ & 109 \\
\hline 21. & I find myself grinding my teeth & $45(39.5)$ & $69(60.5)$ & 114 \\
\hline 22. & $\begin{array}{l}\text { Increase in muscular aches and pains especially in the neck, head, } \\
\text { lower back, shoulders }\end{array}$ & $91(78.4)$ & $25(21.6)$ & 116 \\
\hline 23. & $\begin{array}{l}\text { I am unable to perform tasks as well as I used to, my judgment is } \\
\text { clouded or not as good as it was }\end{array}$ & $68(59.1)$ & $47(40.9)$ & 115 \\
\hline 24. & $\begin{array}{l}\text { I find I have a greater dependency on alcohol, caffeine, nicotine or } \\
\text { drugs }\end{array}$ & $52(44.8)$ & $64(55.2)$ & 116 \\
\hline 25. & $\begin{array}{l}\text { I find that I don't have time for many interests / hobbies outside of } \\
\text { work }\end{array}$ & $93(80.2)$ & $23(19.8)$ & 116 \\
\hline
\end{tabular}

This study has shown that $78 \%$ of the total participants were most prone (severe risk) to stress and stress-related illness. A total of $20 \%$ of the participants were more likely (moderate risk) to develop stress, and just $2 \%$ of the participants had least risk (score 1-4) of stress (Figure).

Figure:-Three categories (with percentages) of risk of stress development among medical students

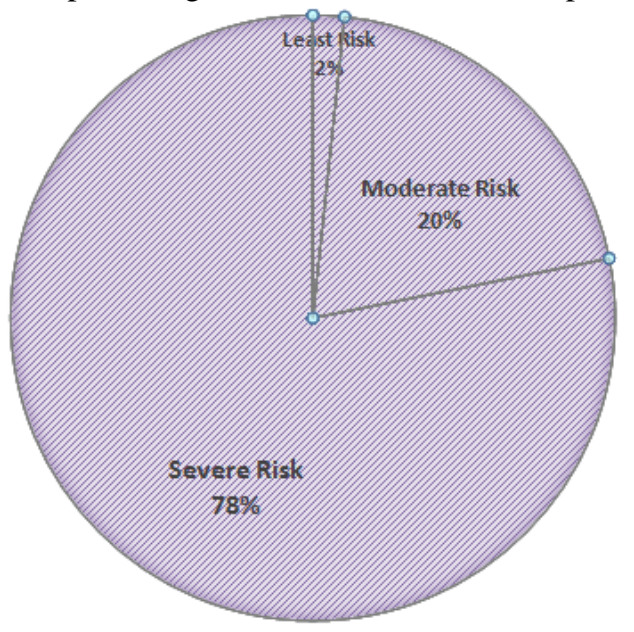

Majority (82.2\%) of the pre-clinical (years 1-3) students were most prone (severe risk) to stress and stress-related illness as compared to $71.7 \%$ students of clinical years (years 4-6). Moreover, $16.4 \%$ ofpre-clinical students and $26.1 \%$ of clinical students were more likely (moderate risk) to experience stress. Prevalence of stress was high in all the medical students irrespective of whether they were in pre-clinical years or clinical years of study, and there was no statistically significant difference $(p=0.405)$ of risk of stress between pre-clinical and clinical students (Table 3 ).

Table 3:-Comparison of the risk of stress development between medical students of pre-clinical years and clinical years

\begin{tabular}{|l|l|l|l|l|l|}
\hline \multirow{2}{*}{$\begin{array}{l}\text { Year of study } \\
\text { during MBBS }\end{array}$} & $\begin{array}{l}\text { Frequency and percentage of the medical students } \\
\text { showing risk of stress development. } \mathbf{n}(\%)\end{array}$ & $\begin{array}{l}\text { Total } \\
\text { Frequency (\%) }\end{array}$ & -value \\
\cline { 2 - 4 } & $\begin{array}{l}\text { Least risk } \\
\text { Score 1-4) }\end{array}$ & $\begin{array}{l}\text { Moderate risk } \\
(\text { Score 5-13) }\end{array}$ & $\begin{array}{l}\text { Severe risk } \\
(\text { Score } \geq 14)\end{array}$ & & \\
\hline $\begin{array}{l}\text { Pre-clinical years } \\
(1-3)\end{array}$ & $1(1.4 \%)$ & $12(16.4 \%)$ & $60(82.2 \%)$ & $73(100 \%)$ & 0.405 \\
\hline Clinical years (4-6) & $1(2.2 \%)$ & $12(26.1 \%)$ & $33(71.7 \%)$ & $46(100 \%)$ & \\
\hline
\end{tabular}


Majority (77\%) of the male students were most prone (severe risk) to develop stress and stress-related illness as compared to $79.6 \%$ of the female students. Furthermore, $20 \%$ of the male students and $20.4 \%$ of the female students were more likely (moderate risk) to experience stress. Prevalence of stress was high in all the participants irrespective of their gender, and there was no statistically significant difference $(p=0.429)$ of risk of stress development between male and female medical students (Table 4).

Table 4:-Comparison of the risk of stress development between male and female medical students

\begin{tabular}{|l|l|l|l|l|l|}
\hline \multirow{2}{*}{ Gender } & $\begin{array}{l}\text { Frequency and percentage of the medical students } \\
\text { showing risk of stress development. n }\end{array}$ & $\begin{array}{l}\text { Total } \\
\text { Frequency }(\%)\end{array}$ & \multirow{2}{*}{-value } \\
\cline { 2 - 4 } \cline { 2 - 4 } & $\begin{array}{l}\text { Least risk } \\
\text { Score 1-4) }\end{array}$ & $\begin{array}{l}\text { Moderate risk } \\
\text { (Score 5-13) }\end{array}$ & $\begin{array}{l}\text { Severe risk } \\
(\text { Score } \geq 14)\end{array}$ & & \\
\hline Male students & $2(3 \%)$ & $13(20 \%)$ & $50(77 \%)$ & $65(100 \%)$ & \\
\hline Female students & $0(0 \%)$ & $11(20.4 \%)$ & $43(79.6 \%)$ & $54(100 \%)$ & 0.429 \\
\hline
\end{tabular}

\section{Discussion:-}

Findings from this study suggest that most of the Saudi medical students are stressed out during their studies. We also found that most of the study participants have high stress irrespective of whether they are in their pre-clinical or clinical years of study. Furthermore, we observed that the risk of stress is high in all the medical students irrespective of their gender.

High (78\%)prevalenceof severe stress in our study participants is similar to the findings of some other studies which have reported $75 \%$ to $90 \%$ risk of stress(Saipanish, 2003; Ofili et al., 2009; Yousafzai et al., 2009; Koochaki et al., 2011). A study conducted by Oboko et al(2015)to investigate the prevalence of stress, stressors and coping strategies among male medical students of Nigeria found that $70.3 \%$ and $22.1 \%$ of medical students perceived their studies and training as very stressful and moderately stressful respectively which is very similar to the findings of our study. However, some studies have reported a lower risk of stress among medical students than our findings. For example, Bhattiet al (2016)have observed $13.3 \%$ risk of severe stress development among medical students of a Pakistani university; although they have used same ISMA stress questionnaire to assess the risk of stress development, the difference in the risk of stress development in their study may be due to differences in the educational curriculum and system, and social and cultural differences. Some other studies(Sherinaet al., 2004; ElGilany et al., 2008) have also reported a lower (41.9\% and $43.7 \%$, respectively) risk of severe stress than our findings $(78 \%)$. These differences may be due to different tools used for assessment of stress in their studies.

We have observed a high (82.2\%) prevalence of severe stress among our pre-clinical (years 1-3) students as compared to $71.7 \%$ prevalence among students of clinical years (years 4-6). The prevalence of severe stress was high among all participants irrespective of whether they were in pre-clinical years or clinical years of MBBS. Contrary to our findings, Oboko et al(2015)observed a significantly higher $(97.3 \%)$ prevalence among pre-clinical students than $88.5 \%$ prevalence among clinical students of a Nigerian medical college. This difference may be attributed to the use of different tools for assessing the risk of stress. Furthermore, it seems as if Nigerian study has combined the very stressful and moderately stressful categories, it is likely they might have over-reportedprevalence of stress than our study.

We found that more than three-fourths of both male and female medical students were stressed during their studies and training, and there was no statistically significant difference between them. These findings are a bit lower than the findings of a Nigerian study (Oboko et al., 2015)which has also described a high prevalence (above 90\%) of stress in medical students irrespective of their gender. This difference may be attributed to the use of differenttools for the assessment of stress; the Nigerian study has used DASS-21 guidelines to classify stress.

Very high prevalence of stress in our participants may be a serious concern as too much stress can affect physical and psychological health of individuals (Folkman, 1984). Perceived stress can create emotional instabilities leading to relationship problems, sleep disturbance, low self-esteem, anxiety, depression, drug addiction, and suicidal tendencies (Shapiro et al., 2000; Moffat et al., 2004; Stecker, 2004; Yousafzai et al., 2009).Stress may also decrease learning ability and academic performance of students. Moreover, it can adversely affect the ability of doctors to provide high quality care(Firth-Cozens, 2003). 
One of the strengths of this study is that we have studied three categories of stress among medical students by using a standardized questionnaire of International Stress Management Association, UK. Additionally, we have compared stress between male and female students, and also between pre-clinical and clinical students. A relatively small sample size as compared to other similar studies may be one of the limitations. Cross-sectional nature of this study may also limit the generalizability of the results of this study. Reporting bias cannot be entirely eliminated as we have used self-administered questionnaire; respondents' understanding of the questions or their wish to report their emotions in a certain way may have caused some degree of bias. Some possible confounding factors e.g. psychiatric problems and current emotional states of the participants, teaching styles and faculty characteristics were not considered for this study.

\section{Conclusions:-}

This study has shown that most of the undergraduate medical students of Saudi Arabia perceive their studies and training as either moderately or severely stressful. The risk of stress development is high in most of the participants irrespective of their gender or year of study during MBBS. Since medical studies are intrinsically stressful and there are some stressors which are unavoidable, it is recommended that stress management courses should be included in the undergraduate medical curriculum. It is also important that we cooperatively discuss these results with students and offer them support in the form of counseling. Further studies are recommended to investigate stressors, consequences of stress, coping strategies, prevention and treatment of stress.

\section{References:-}

1. Aktekin, M., Karaman, T., Senol, Y. Y., Erdem, S., Erengin, H. and Akaydin, M. (2001). Anxiety, depression and stressful life events among medical students: a prospective study in Antalya, Turkey. Medical education, 35(1): 12-7.

2. Al-Dubai, S. A. R., Al-Naggar, R. A., Alshagga, M. A. and Rampal, K. G. (2011). Stress and coping strategies of students in a medical faculty in Malaysia. Malaysian Journal of Medical Sciences, 18(3): 57-64.

3. Ayyaz Ahmed Bhatti, Mahvash Khan, Hamid Bashir, S. A. (2016). Risk of development of stress in university students. Rawal Medical Journal, 41(4): 483-486.

4. Bansal, C.P. and Bhave, S.Y. (2006).Stress in Adolescents and its Management.Textbook of Adolescent Medicine. New Delhi: Jaypee Brothers Medical Publishers.Pp.844-53.

5. Dyrbye, L. N., Thomas, M. R. and Shanafelt, T. D. (2006). Systematic Review of Depression, Anxiety, and other indicators of Psychological Distress among U.S. and Canadian Medical Students. Academic Medicine, 81(4): 354-373.

6. El-Gilany, A.H., Amr, M. and Hammad, S. (2008). Perceived stress among male medical students in Egypt and Saudi Arabia: effect of sociodemographic factors. Annals of Saudi medicine, 28(6): 442-8.

7. Firth-Cozens, J. (2003). Doctors, their wellbeing, and their stress. BMJ (Clinical research ed.), 326(7391), pp. $670-671$.

8. Folkman, R. S. L. and S. (1984) Stress, Appraisal, and Coping. New York: Springer Publishing Company.

9. Stress questionnaire. (2013).International Stress Management Association UK.

10. Koochaki, G. M., Charkazi, A., Hasanzadeh, A., Saedani, M., Qorbani, M. and Marjani, A. (2011). Prevalence of stress among Iranian medical students: a questionnaire survey. Eastern Mediterranean Health Journal, 17(7): 593-598.

11. Le Fevre, M., Kolt, G. S. and Matheny, J. (2006). Eustress, distress and their interpretation in primary and secondary occupational stress management interventions: which way first? Journal of Managerial Psychology. Emerald Group Publishing Limited, 21(6): 547-565.

12. Moffat, K. J., McConnachie, A., Ross, S. and Morrison, J. M. (2004). First year medical student stress and coping in a problem-based learning medical curriculum. Medical Education, 38(5): 482-491.

13. Oboko, O.A., Theodora, O.E., Oboko, O.O., and Monday, I.B. (2015). Prevalence of stress, stressors and coping strategies among medical students in a Nigerian medical school. African Journal of Medical and Health Sciences, 14(1): 29-34. doi: 10.4103/2384-5589.153384.

14. Ofili AN, Oriaifo I, Okungbowa E, E. E. (2009). Stress and psychological health of medical students in a Nigerian university. Niger J Clin Pract., 12(2): 128-33.

15. Saipanish, R. (2003). Stress among medical students in a Thai medical school. Medical teacher, 25(5): 502506.

16. Shapiro, S. L., Shapiro, D. E. and Schwartz, G. E. (2000). Stress management in medical education: a review of the literature. Academic medicine : journal of the Association of American Medical Colleges, 75(7): 748-59. 
17. Sherina, M. S., Rampal, L. and Kaneson, N. (2004). Psychological stress among undergraduate medical students. The Medical journal of Malaysia, 59(2): 207-211.

18. Stecker, T. (2004). Well-being in an academic environment. Medical Education, 38(5): 465-478.

19. Stewart, Lam, Betson and Wong (1999). A prospective analysis of stress and academic performance in the first two years of medical school. Medical Education, 33(4): 243-250. doi:10.1046/j.1365-2923.1999.00294.x

20. Waghachavare, V. B., Dhumale, G. B., Kadam, Y. R. and Gore, A. D. (2013). A study of stress among students of professional colleges from an urban area in India. Sultan Qaboos University Medical Journal, 13(3): 422429.

21. Yousafzai, A. W., Ahmer, S., Syed, E., Bhutto, N., Iqbal, S., Siddiqi, M. N. and Zaman, M. (2009). Well-being of medical students and their awareness on substance misuse: a cross-sectional survey in Pakistan. Annals of general psychiatry, 8 , p. 8. 